\title{
When the going gets easier
}

Written by: Harri Pursiainen, Permanent Secretary, Ministry of Transport and Communications of Finland

Last update: 2 March 2020

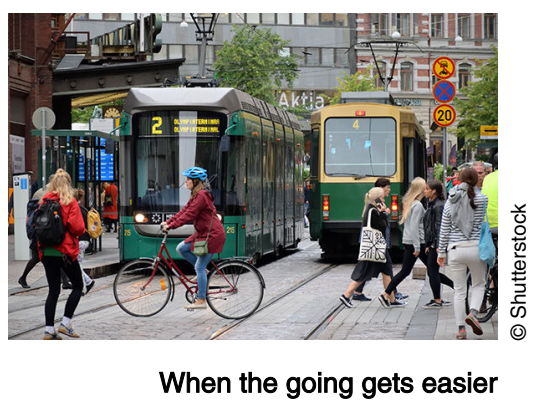

Digitalisation, climate change and urbanisation are changing our lives and forcing us to find new ways to move people and goods. We must cut down on carbon emissions, and make traffic safer and more efficient than before. Digital tools will help us with this. After all, small, wallet-sized devices now enable nearinstant data transfer and internet connections all over the world. Mobile phone technology provides us with services we could not even have dreamt of a few years ago.

Today, I would like to see this same, amazing change happen in the transport sector. I believe that digitalisation enables us to transform our transport sector into a sustainable, customer-centric mobility system that is more efficient.

\section{From data to new services}

Data is key to changing our transportation system and Finland's new landmark transport legislation is paving the way. Finland is the first country in the world to use legislation in such a way as to mesh together all different transport modes from taxis and city trams to long-distance trains and bike shares so that users can get around and transport goods from A to B as frictionlessly as possible. The Finnish Act on Transport Services regards the entire transport system as a single entity.

It requires all transport service providers to open up their essential data, such as information on routes, stops, timetables, prices, availability and accessibility in a machine-readable form via open interfaces. By sharing data, service providers can use their transportation fleet more effectively in moving goods and passengers. 
The act also requires transport service providers to have compatible systems and grant each other access to their ticket and payment system interfaces. The government has given service providers an incentive to do this by making interoperability a criterion for public procurement. Service providers can sell customers tickets for other transport modes-a train vendor can sell you a train as well as the bus ticket you need to get to your destination from the train station, for instance. This makes going from $A$ to $B$ as easy and user-friendly as possible. Called Mobility as a Service or MaaS, this shifts the notion of transportation from a traditional one of separate, autonomous transport modes to that of transportation as a service for the customer-hopefully the best one. This is the principle of the new transport act.

Most parts of the act entered into force in July 2018, and so far, it has largely met our expectations. In keeping with the data regulation in the Act, mobility service providers have opened up a large number of interfaces for exchanging essential data and the opening of sales interfaces has also started. According to feedback from operators, new services and systems have been actively developed: we are witnessing a promising start.

Mobility as a Service (MaaS) makes it easier for people and goods to move around but it will also cut down on carbon emissions. This new system transforms mobility into a travel chain that combines public transport with private mobility services in a way that is user-driven, cost-efficient, attractive and sustainable.

Why sustainable? Because a system that makes it easy to get from A to B by using a combination of, for instance, metro, shared bike and taxi is an attractive alternative to driving your own car. Moreover, this system encourages users to choose transport options with the lowest emissions by making it the easiest and cheapest way to travel.

MaaS can be a viable solution in rural areas too. Several interesting pilot projects are tackling the challenge of combining rides and transport in collaboration with public and private transport operators. Have a look at the Open Arctic MaaS project in Lapland as well as the Alpio project. Both experiment with different ways of organising mobility services in less densely populated areas.

\section{Do we dare take a holistic view?}

Legislation is only one part of the solution. It can enable change but, alone, is not enough to make it truly happen. That requires co-operation-between public and private operators as well as among different industries and levels of government.

Although what has been described here is a local, Finnish solution, the challenges we face are global. So should the solutions. I am confident that we can find common ways and best practices-the OECD's horizontal project on digitalisation has proven that in many fields undergoing digital disruption. 
We need to have the courage to change the way we do the most fundamental things, even if it might not please everyone. In the history of transport, many things we now take for granted started out as radical, daring ideas.

\section{References:}

- Visit: https://maas.global/ https://maas.global/

- Visit: https://www.lvm.fi/en/home https://www.lvm.fi/en/home @OOECD Observer March 2019 